\title{
The Klotho protein supports redox balance and metabolic functions of cardiomyocytes during ischemia/reperfusion injury
}

\author{
Agnieszka Olejnik®, Marta Banaszkiewicz@, \\ Anna Krzywonos-Zawadzka๑, Iwona Bil-Lula@
}

Division of Clinical Chemistry and Laboratory Haematology, Department of Medical Laboratory Diagnostics, Faculty of Pharmacy, Wroclaw Medical University, Wroclaw, Poland

\begin{abstract}
Background: Acute heart ischemia followed by reperfusion leads to overproduction of reactive oxygen/ Initrogen species (ROS/RNS), disrupted expression of nitric oxide synthase (NOS) and unbalanced glucose metabolism. Klotho is a membrane-bound or soluble protein that exerts protective activity in many organs. While Klotho is produced mainly in the kidneys and brain, it has been recently proven that Klotho is expressed in the cardiomyocytes as well. This study aimed to show the influence of the Klotho protein on oxidative/nitrosative stress and metabolic function of the cardiomyocytes subjected to ischemia/reperfusion (I/R) injury.

Methods: Human cardiac myocytes underwent in vitro chemical $I / R$ (with sodium cyanide and 2-deoxyglucose), in the presence or absence of the recombinant human Klotho protein. The present study included an investigation of cell injury markers, level of nicotinamide adenine dinucleotide phosphate (NADPH) oxidase (NOX), level of oxidative/nitrosative stress and metabolic processes of the cardiomyocytes.

Results: Administration of Klotho protein resulted in mitigation of injury, decreased level of NOX2 and NOX4, reduced generation of ROS/RNS and hydrogen peroxide $\left(\mathrm{H}_{2} \mathrm{O}_{2}\right)$, decreased expression of inducible NOS and limited production of nitrates/nitrites in cells under $I / R$. Glucose uptake and lactate production in the cardiomyocytes subjected to $I / R$ were normalized after Klotho supplementation.

Conclusions: The Klotho protein participates in the regulation of redox balance and supports metabolic homeostasis of the cardiomyocytes and hence, contributes to protection against I/R injury. (Cardiol J 2022; 29, 5: 836-849)
\end{abstract}

Key words: Klotho protein, cardioprotection, heart, ischemia/reperfusion injury, oxidative stress, nitrosative stress

\section{Introduction}

Acute heart ischemia followed by reperfusion (I/R) leads to the interruption of coronary blood flow followed by subsequent restoration of perfusion, resulting in cardiac damage [1]. Heart $\mathrm{I} / \mathrm{R}$ injury causes an excessive formation of reactive oxygen species (ROS) [2], reactive nitrogen species (RNS), degradation of cardiac contractile proteins by proteolytic enzymes and necrotic cell death $[3,4]$.

Klotho is a membrane or soluble protein and its protective action is important for the functioning of many organs $[5,6]$. Klotho is produced mainly in the kidneys and brain $[5,6]$. It was previously shown that a protective, compensatory produc-

Address for correspondence: PhD, DSc, Associate Professor Iwona Bil-Lula, Division of Clinical Chemistry and Laboratory Haematology, Department of Medical Laboratory Diagnostics, Wroclaw Medical University, ul. Borowska 211A, 50-556 Wrocław, Poland, tel: +48 784-06-21, fax: +48 784-00-54, e-mail: iwona.bil-lula@umw.edu.pl

Received: 21.04.2021 Accepted: 5.12.2021 Early publication date: 28.12.2021

This article is available in open access under Creative Common Attribution-Non-Commercial-No Derivatives 4.0 International (CC BY-NC-ND 4.0) license, allowing to download articles and share them with others as long as they credit the authors and the publisher, but without permission to change them in any way or use them commercially. 


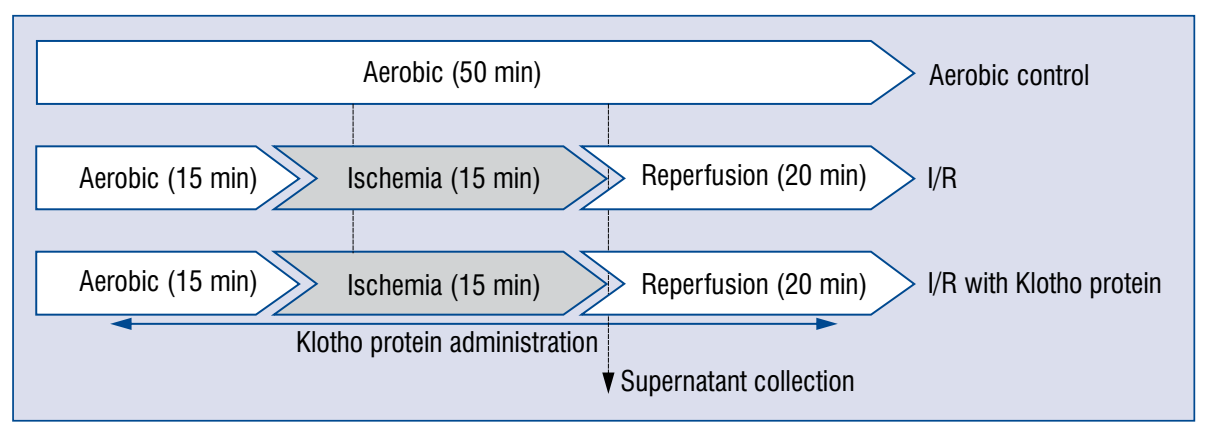

Figure 1. Experimental protocol for in vitro chemical ischaemia/reperfusion (I/R) injury of cardiomyocytes with and without Klotho administration.

tion of Klotho takes place in the cardiomyocytes during I/R. Thus, Klotho was proposed as a biomarker of heart damage [7]. In the current study, it is hypothesised that Klotho could protect the cardiomyocytes from I/R injury and participates in the reduction of formation and activity of such molecules as ROS and RNS. Since lactate is considered an important regulatory molecule of intermediate metabolism involved in $\mathrm{I} / \mathrm{R}$, and glucose metabolism is a key process in ischemic heart disease $[8,9]$. It is also proposed herein, that Klotho supports the metabolic functions of injured cells.

This study aimed to examine the influence of the Klotho protein on oxidative/nitrosative stress and metabolic functions of the cardiomyocytes subjected to I/R injury.

\section{Methods}

\section{Cell culture}

The primary human cardiac myocytes (HCM) were purchased from ScienCell Research Laboratories (Carlsbad, CA, USA) and cultured under standard conditions $[10]\left(37^{\circ} \mathrm{C}\right.$, water-saturated, $5 \% \mathrm{CO}_{2}$ atmosphere), according to the manufacturer's instructions. Cells were passaged at $90 \%$ confluence using $0.25 \%$ trypsin-EDTA (Sigma-Aldrich, St. Louis, MO, USA).

\section{The protocol of in vitro chemical $I / R$ injury of cardiomyocytes}

Cardiac myocytes in culture underwent in vitro chemical I/R per the guidelines for experimental models of myocardial ischemia and infarction [11]. Figure 1 shows the experimental protocol scheme. Briefly, HCM in the I/R groups underwent $15 \mathrm{~min}$ of aerobic stabilization, 15 min of in vitro chemical ischemia and $20 \mathrm{~min}$ of reperfusion $[3,7]$ in the absence or presence of $1 \mu \mathrm{g} / \mathrm{mL}[7,12]$ of the Recombinant Human Klotho Protein (R\&D Sys- tems, 5334-KL-025). The aerobic stabilization and reperfusion were performed in 4-(2-hydroxyethyl)1-piperazineethanesulfonic acid (HEPES) buffer (5.5 mmol/L HEPES, $63.7 \mathrm{mmol} / \mathrm{L} \mathrm{CaCl}_{2}, 5 \mathrm{mmol} / \mathrm{L}$ $\mathrm{KCl}, 2.1 \mathrm{mmol} / \mathrm{L} \mathrm{MgCl}_{2}, 5.5 \mathrm{mmol} / \mathrm{L}$ glucose, $10 \mathrm{mmol} / \mathrm{L}$ taurine) containing additional $55 \mu \mathrm{mol} / \mathrm{L}$ $\mathrm{CaCl}_{2}$ and $0.75 \mathrm{mg} / \mathrm{mL}$ BSA. During in vitro chemical ischemia, cells were incubated in HEPES buffer containing $4.4 \mathrm{mmol} / \mathrm{L} 2$-deoxyglucose (to inhibit glycolysis) and $4.0 \mathrm{mmol} / \mathrm{L}$ sodium cyanide (cellular respiration inhibitor) [3]. The optimal ischemia duration (15 min) was previously established experimentally by measuring the activity of lactate dehydrogenase (LDH) released from cells as a marker of cell injury (data not shown). In the Klotho experimental group (I/R+Klotho), cells underwent $\mathrm{I} / \mathrm{R}$ procedure in the presence of Klotho protein in the buffers $(1 \mu \mathrm{g} / \mathrm{mL}$ final concentration) during the entire protocol. Cells from the aerobic control group were incubated aerobically for $50 \mathrm{~min}$ in HEPES buffer at real time (RT). Then, cells from all groups were homogenized mechanically with a hand-held homogeniser in the homogenization buffer.

\section{Klotho mRNA expression}

The total RNA from HCM was isolated with TRIZOL reagent (Thermo Fisher Scientific, Waltham, MA, USA) according to the manufacturer's instructions. A microvolume ultraviolet spectrophotometer (NanoDrop Lite, Thermo Scientific) was used to evaluate the concentration and purity of RNA. To prepare cDNA, reverse transcription of pure RNA samples (100 ng) was conducted using the iScript cDNA Synthesis Kit (BioRad, Hercules, CA, USA), according to the instructions provided. The reverse transcription was carried out at $42^{\circ} \mathrm{C}$ for $30 \mathrm{~min}$ and inactivated at $85^{\circ} \mathrm{C}$ for $5 \mathrm{~min}$. Real-time quantitative polymerase chain reaction (RT-qPCR) and CFX96 Real-Time System 
(BioRad) were used for the analysis of the Klotho gene expression. The expression level of glucose-6-phosphate dehydrogenase (G6PD) gene was used as an internal reference. The final volume of the reaction mix was $30 \mu \mathrm{L}$ and included iTag Universal Sybr Green Supermix with ROX (BioRad), forward and reverse primers $(250 \mathrm{nmol} / \mathrm{L}$ final conc.), water and cDNA (100 ng). The primers were designed by us and synthesized by TIB Molbiol (TIB Molbiol, Berlin, Germany). The amount of Klotho mRNA relative to G6PD was calculated as $2^{-\Delta \mathrm{Ct}}$.

\section{Klotho protein production}

The concentration of Klotho protein in cell homogenates was measured using Sandwich $\mathrm{Hu}-$ man Klotho ELISA Kit from Biorbyt (orb397071, Biorbyt Ltd., UK), according to the manufacturer's instructions. The color strength in each well was proportional to the quantity of Klotho protein and was normalized to total protein concentration.

\section{LDH activity measurement}

A Lactate Dehydrogenase Activity Assay Kit (Sigma-Aldrich, St. Louis, MO, USA) was used to determine the activity of LDH in cells, according to the manufacturer's instructions. $\mathrm{LDH}$ is a stable cytosolic enzyme that is released upon membrane damage/permeability or cell lysis and serves as a marker of cell damage. LDH activity was assessed in cell supernatants and normalized to total protein concentration.

\section{The level of NOX2 and NOX4}

To assay nicotinamide adenine dinucleotide phosphate (NADPH) oxidase 2 (NOX2) and NADPH oxidase 4 (NOX4) expression in the cardiomyocytes, Human NADPH Oxidase 2 (NOX2) ELISA Kit and Human NADPH Oxidase 4 (NOX4) ELISA Kit (all from SunLong Biotech Co., Zhejiang, China) in accordance to the manufacturer's instructions were used. These ELISA kits use Sandwich-ELISA as the method. The optical density was measured spectrophotometrically at a wavelength of $450 \mathrm{~nm}$. The optical density values were proportional to the concentration of NOX2 and NOX4, respectively. NOX2 and NOX4 levels were assessed in cell supernatants and normalized to total protein concentration in each sample.

\section{Assessment of oxidative} and nitrosative stress

An OxiSelect ${ }^{\mathrm{TM}}$ In Vitro ROS/RNS Assay Kit (Cell Biolabs, San Diego, USA) was used to assess the influence of Klotho on the levels of total ROS/
/RNS and hydrogen peroxide $\left(\mathrm{H}_{2} \mathrm{O}_{2}\right)$ in the cardiomyocytes. The assay measures total ROS/RNS or $\mathrm{H}_{2} \mathrm{O}_{2}$ using a proprietary fluorogenic probe - dichlorodihydrofluorescein (DCFH) DiOxyQ. In the presence of ROS and RNS, the DCFH is rapidly oxidised to the highly fluorescent 2',7'-dichlorodihydrofluorescein. The DCFH-DiOxyQ probe can react with $\mathrm{H}_{2} \mathrm{O}_{2}$, peroxyl radical (ROO·), nitric oxide (NO), and peroxynitrite anion $\left(\mathrm{ONOO}^{-}\right)$. These free radical molecules are representative of both ROS and RNS, thus allowing for the measurement of the total free radical population within a sample. Using the $\mathrm{H}_{2} \mathrm{O}_{2}$ standards and standard curve, the level of $\mathrm{H}_{2} \mathrm{O}_{2}$ was also assessed. Fluorescence intensity was proportional to the total ROS/RNS or $\mathrm{H}_{2} \mathrm{O}_{2}$ levels within the sample. Total ROS/RNS and $\mathrm{H}_{2} \mathrm{O}_{2}$ levels were assessed in cell supernatants and normalized to total protein concentration. However, there are some limitations in the use of $\mathrm{DCFH}$, for example, $\mathrm{DCFH}$ does not directly react with $\mathrm{H}_{2} \mathrm{O}_{2}$ to form the fluorescent product [13]. Therefore, DCFH results were interpreted as an indirect measure of $\mathrm{H}_{2} \mathrm{O}_{2}$.

\section{Measurement of TAC of cardiomyocytes}

An OxiSelect ${ }^{\mathrm{TM}}$ Total Antioxidant Capacity Assay Kit (Cell Biolabs, San Diego, USA) was used to assess the influence of Klotho on the oxidative stress inhibition during I/R. Measurement of the total non-enzymatic antioxidant capacity is indicative of the cells' ability to counteract induced oxidative stress. Total antioxidant capacity (TAC) assay is based on the reduction of copper (II) to copper (I) by the antioxidants present in the sample. The TAC level was measured in cell homogenates, expressed as $\mu \mathrm{M}$ of Copper Reducing Equivalents (CRE) and normalized to $\mu \mathrm{L}$ of cell homogenates.

\section{Immunofluorescence staining for iNOS}

Human cardiac myocytes were cultured in a 96 -well plate at a density of $5.5 \times 10^{3}$ cells per well for $24 \mathrm{~h}$, and then subjected to in vitro chemical I/R according to the protocol shown in Figure 1. Then, cells were subjected to fixation at RT for $15 \mathrm{~min}$, with $500 \mu \mathrm{L} /$ well of $4 \%$ paraformaldehyde and were incubated with a blocking buffer for $1 \mathrm{~h}$ at RT. Primary antibodies, mouse anti-inducible nitric oxide synthase (iNOS) 1:1000 (ab21775, Abcam, UK), were incubated at $4^{\circ} \mathrm{C}$ overnight and then washed with phosphate buffered saline (PBS). Then, the secondary antibodies - goat anti-mouse IgG 1:500 (ab96872, Abcam, UK) labelled with DyLight ${ }^{\circledR} 550$ - were added and incubated at RT for $45 \mathrm{~min}$. Myocytes were stained with DAPI (4',6-diamidino- 
2-phenylindole, Sigma-Aldrich) 1:1000 for $15 \mathrm{~min}$ in the dark and rinsed with PBS to visualize the cells' nuclei. A Spark Multimode Microplate Reader (Tecan Trading AG, Switzerland) was used to read the signal emitted. To visualize the expression of iNOS (red fluorescence), Thunder Leica Imager (Leica Microsystems) was used. The number of cells was assessed by measuring the fluorescence of the cells' nuclei stained by DAPI (blue fluorescence). The expression of iNOS protein in the aerobic and $\mathrm{I} / \mathrm{R}$ groups was assessed by measuring red fluorescence intensity expressed in arbitrary units (AU) and normalized to the number of cells (blue fluorescence) in each well.

\section{Nitrates and nitrites $\left(\left(\mathrm{NO}_{\mathrm{x}}\right)^{-}\right)$level}

The amount of total $\left(\mathrm{NO}_{\mathrm{x}}\right)^{-}$(oxidative products of endogenous NO) in cells serves as a measure of NO production $[3,14]$. A commercially available Nitric Oxide Assay Kit (Abcam, Cambridge, MA, USA) according to the manufacturer's instructions for measurement of $\left(\mathrm{NO}_{\mathrm{x}}\right)^{-}$level was used. The $\left(\mathrm{NO}_{\mathrm{x}}\right)^{-}$level was assessed in cell homogenates and normalized to total protein concentration.

The measurement of glucose uptake and lactate production in cardiomyocytes

To assess the metabolic status of cells, glucose uptake and lactate production were measured. 2-deoxyglucose (2DG) uptake was studied using a bioluminescent Glucose Uptake-Glo ${ }^{\mathrm{TM}}$ Assay (Promega, Madison, WI, USA). Briefly, 2DG is taken up by glucose transporters and metabolized to 2-DG-6-phosphate (2DG6P) in the same manner as glucose. 2DG6P cannot be further metabolized, and thus accumulates within the cells. Accumulated 2DG6P is directly proportional to 2DG (or glucose) uptake by cells and the luminescence is proportional to the concentration of 2DG6P. HCM were cultured in a 96 -well plate at a density of $5.5 \times 10^{3}$ cells per well for $24 \mathrm{~h}$ and then subjected to in vitro chemical $\mathrm{I} / \mathrm{R}$ injury according to the protocol shown in Figure 1. The cell confluence in each well was measured. Afterwards, $50 \mu \mathrm{L}$ of $1 \mathrm{mM} 2 \mathrm{DG}$ per well for $10 \mathrm{~min}$ was added and accumulated 2DG6P was measured using a luminescence assay, according to the manufacturer's guidelines. Data were normalized to the percent of cell confluence and expressed in relative light units (RLU) in the case of each well. Lactate production in the cardiomyocytes was examined using an L-Lactate Assay Kit (ab65331, Abcam, UK) according to the manufacturer's instructions. The lactate concentration was assessed in cell supernatants and normalized to total protein concentration.

\section{Determining the total protein concentration}

The Bradford method [15] was used to determine protein concentration in cell homogenates and supernatants. Bio-Rad Protein Assay Dye Reagent (BioRad) and Spark Multimode Microplate Reader (Tecan Trading AG, Switzerland) for measuring total protein concentration were used.

\section{Statistical analysis}

GraphPad Prism 6 software (GraphPad Software, San Diego, CA, USA) was used for statistical analysis of the results. To assess the normality of variance changes, either the Shapiro-Wilk normality test or the Kolmogorov-Smirnov test was used. Then, ANOVA or nonparametric test with post hoc tests for comparison of data between measurement groups were used. Correlations were assessed using the Pearson or Spearman test, as appropriate. Results were expressed as mean \pm standard error of mean (SEM), with a value of $\mathrm{p}<0.05$ being regarded as statistically significant.

\section{Results}

\section{Reduced injury of cardiac cells in the presence of Klotho}

The expression of the Klotho gene (Fig. 2A) and the production of the Klotho protein (Fig. 2B) were increased in cells subjected to $\mathrm{I} / \mathrm{R}$ in comparison to the aerobic control group. LDH activity in supernatants was significantly higher in the I/R group compared to the aerobic (Fig. 2C). The expression of the Klotho gene positively correlated with LDH activity ( $\mathrm{p}=0.0001, \mathrm{r}=0.63$ ) (Fig. 2D). The administration of exogenous recombinant human Klotho protein during $\mathrm{I} / \mathrm{R}$, regulated the expression of the Klotho gene (Fig. 2A) and protein (Fig. 2B) in the cardiomyocytes, and significantly reduced their damage (Fig. $2 \mathrm{C}$ ).

\section{The level of NOX2 and NOX4 \\ in cell supernatants}

The level of NOX2 was significantly higher in cells injured by I/R (Fig. 3A). NOX2 level (Fig. 3A) and NOX4 level (Fig. 3B) were lower in the I/R+ Klotho group in comparison to I/R. Additionally, the administration of Klotho during $\mathrm{I} / \mathrm{R}$ resulted in a lower NOX4 level than in cells maintained in aerobic conditions (Fig. 3B). The expression 


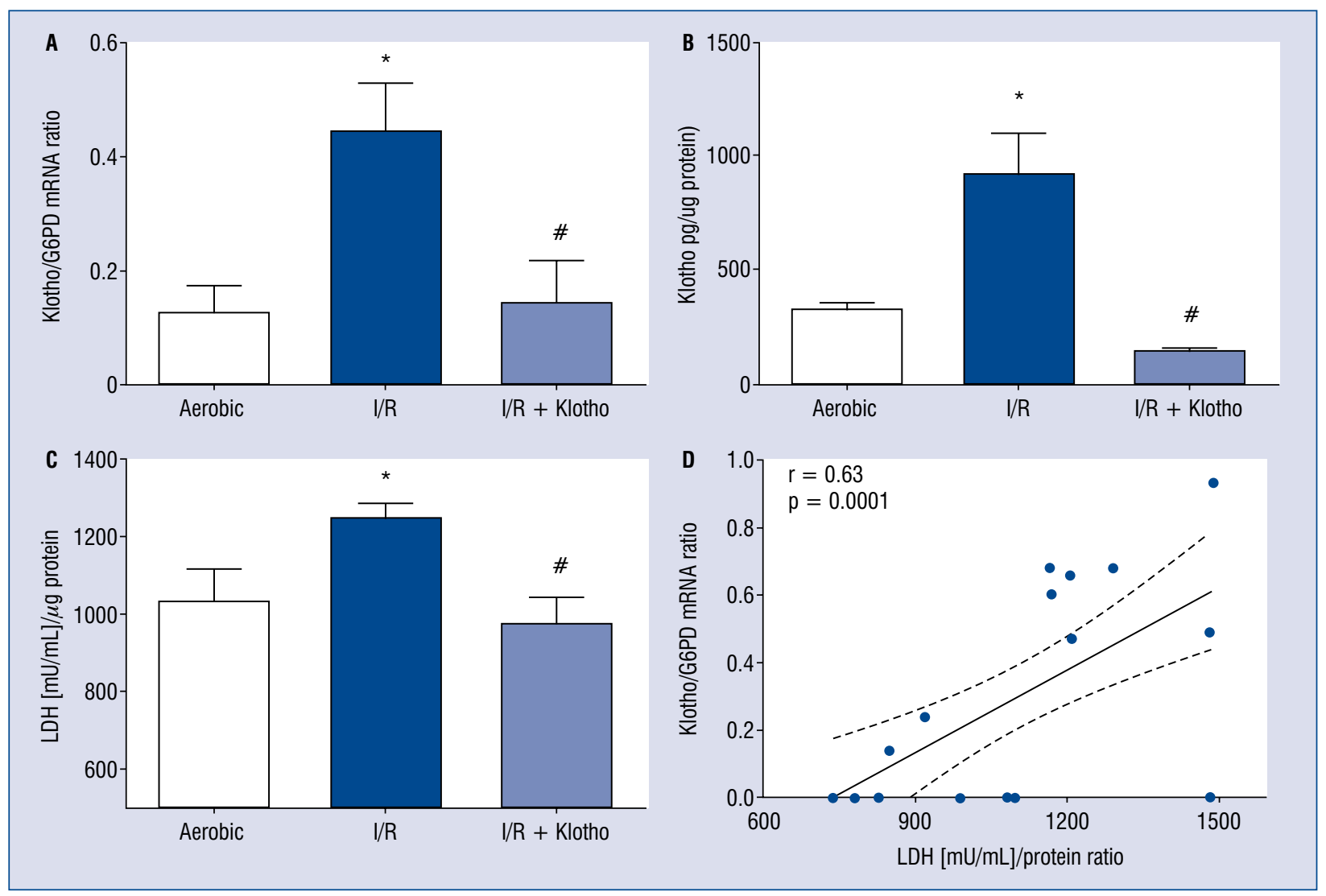

Figure 2. The expression of Klotho gene and protein in the cardiomyocytes during ischemia/reperfusion (I/R) injury. A. The expression of the Klotho gene in human cardiomyocytes was examined by real time quantitative polymerase chain reaction (RT-qPCR) and normalized to glucose-6-phosphate dehydrogenase (G6PD); $B$. The production of the Klotho protein in the cardiomyocytes tested by ELISA; C. Lactate dehydrogenase (LDH) activity in cell supernatants as a marker of cell death. LDH activity was normalized to the total protein concentration; D. Correlation of the Klotho gene expression and LDH activity; $\mathrm{mU} / \mathrm{mL}-$ milli international enzyme units per milliliter; ${ }^{*} \mathrm{p}<0.05$ vs. the aerobic control group; $\# \mathrm{p}<0.05$ vs. ischemia/reperfusion; mean $\pm \mathrm{SEM} ; \mathrm{n}=8-20$.

of NOX2 in the cardiomyocytes was about 9-fold higher than the expression of NOX4.

\section{Reduced oxidative and nitrosative stress in cardiac cells treated with Klotho}

The total ROS and RNS level (Fig. 4A) and $\mathrm{H}_{2} \mathrm{O}_{2}$ level (Fig. 4B) were significantly higher in the I/R group compared to the aerobic control group. There was a positive correlation between total ROS/RNS and $\mathrm{H}_{2} \mathrm{O}_{2}$ levels $(\mathrm{r}=0.94, \mathrm{p}<0.0001)$ (Fig. 4C). The administration of Klotho protein effectively reduced the production of ROS/RNS (Fig. 4A) and $\mathrm{H}_{2} \mathrm{O}_{2}$ (Fig. 4B), and enhanced TAC (Fig. 5A) of cells subjected to I/R. TAC of the cardiomyocytes negatively correlated with LDH activity $(\mathrm{r}=-0.46, \mathrm{p}=0.0106$; Fig. $5 \mathrm{~B}), \mathrm{ROS} / \mathrm{RNS}$ level $(\mathrm{r}=-0.49, \mathrm{p}=0.0278$; Fig. $5 \mathrm{C}), \mathrm{H}_{2} \mathrm{O}_{2}$ level ( $\mathrm{r}=-0.73, \mathrm{p}<0.0001$; Fig. $\left.5 \mathrm{D}\right)$, and with NOX2 $(\mathrm{r}=-0.49, \mathrm{p}=0.0409)$ and NOX4 $(\mathrm{r}=-0.65, \mathrm{p}=0.0037)$ levels (Fig. 5E).

\section{The expression of iNOS protein} in cardiomyocytes

The expression of iNOS protein in the cardiomyocytes tested by immunofluorescence staining was significantly enhanced in the I/R group compared to the aerobic control group (Fig. 6A, 6D). There was a positive correlation between the iNOS expression and the ROS/RNS level $(r=0.59$, $\mathrm{p}=0.0075$; Fig. 6B) and $\mathrm{H}_{2} \mathrm{O}_{2}$ level $(\mathrm{r}=0.59$, $\mathrm{p}=0.0018$; Fig. $6 \mathrm{C}$ ). Klotho supplementation during $\mathrm{I} / \mathrm{R}$ reduced the expression of iNOS in the cardiomyocytes (Fig. 6A, 6D).

\section{The production of NO in cardiac cells}

The amount of total $\left(\mathrm{NO}_{\mathrm{x}}\right)^{-}$served as the measure of $\mathrm{NO}$ production. The level of $\left(\mathrm{NO}_{\mathrm{x}}\right)^{-}$ was significantly higher in cells subjected to $\mathrm{I} / \mathrm{R}$ compared to the aerobic group (Fig. 7A). The level of $\left(\mathrm{NO}_{\mathrm{x}}\right)^{-}$positively correlated with $\mathrm{LDH}$ activity 


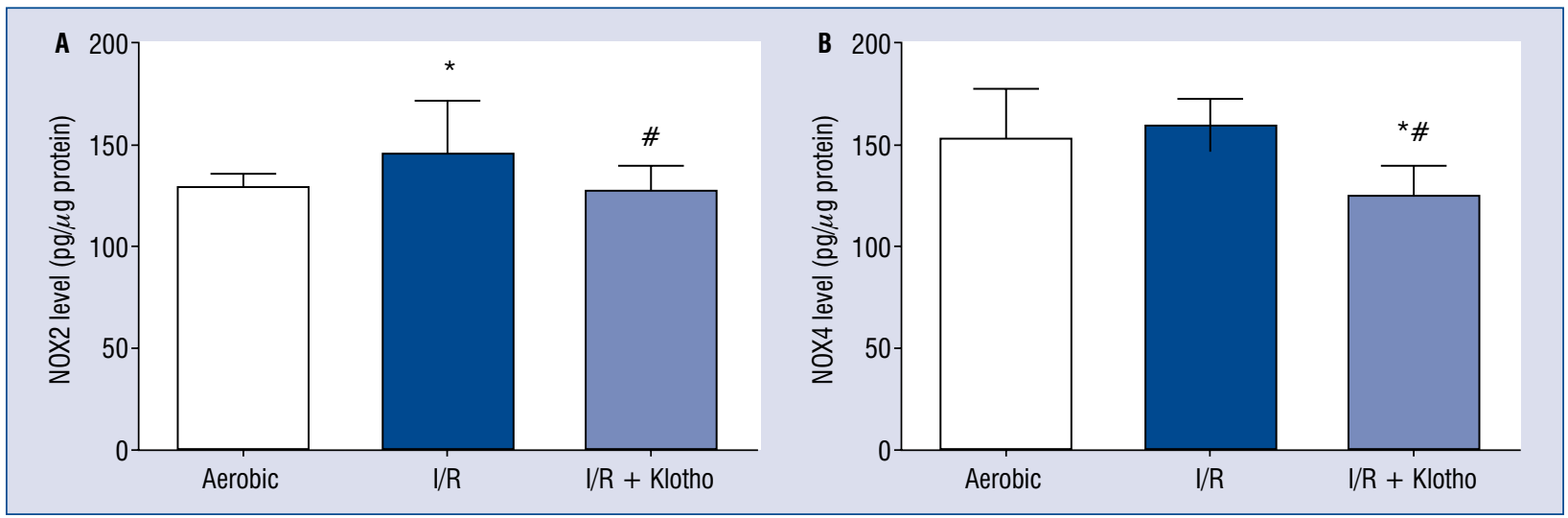

Figure 3. The level of NADPH oxidase 2 (NOX2) and NADPH oxidase 4 (NOX4) in cell supernatants. A. The level of NOX2 in cell supernatants normalized to total protein concentration; $B$. The level of NOX4 in cell supernatants normalized to total protein concentration; NADPH - nicotinamide adenine dinucleotide phosphate; ${ }^{*} p<0.05$ vs. aerobic control; \#p < 0.05 vs. ischemia/reperfusion (I/R); mean $\pm \mathrm{SEM}$; $\mathrm{n}=7-16$.
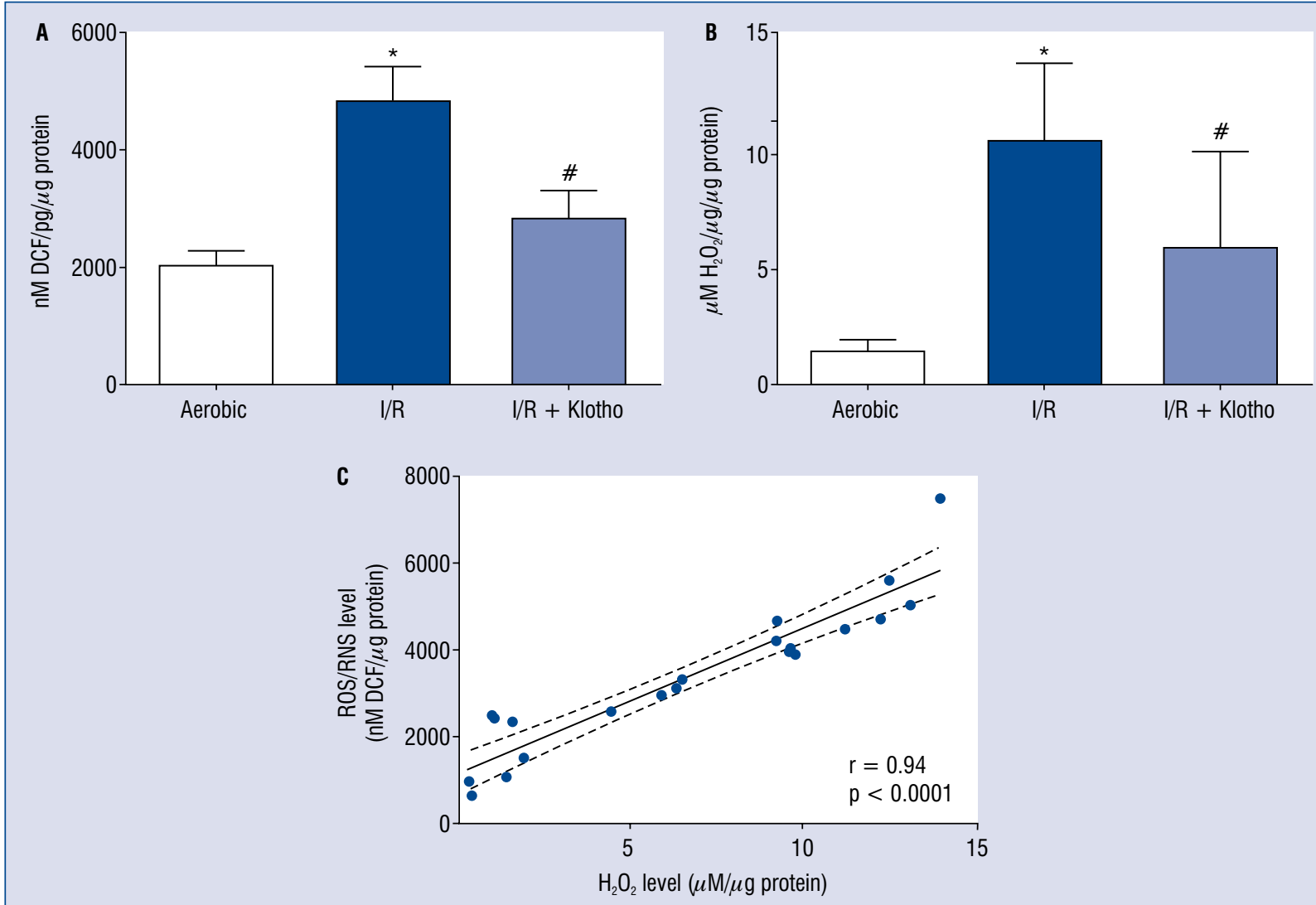

Figure 4. Oxidative and nitrosative stress in cardiac cells. A. The total reactive oxygen species (ROS) and reactive nitrogen species (RNS) level in cell supernatants expressed as nM of 2', 7'-dichlorodihydrofluorescein (DCF) and normalized to total protein concentration; B. The level of hydrogen peroxide $\left(\mathrm{H}_{2} \mathrm{O}_{2}\right)$ in cell supernatants normalized to total protein concentration; C. Correlation of ROS/RNS and $\mathrm{H}_{2} \mathrm{O}_{2}$ level; ${ }^{*} \mathrm{p}<0.05$ vs. aerobic control; \#p $<0.05$ vs. ischemia/reperfusion; mean $\pm \mathrm{SEM} ; \mathrm{n}=5-10$. 

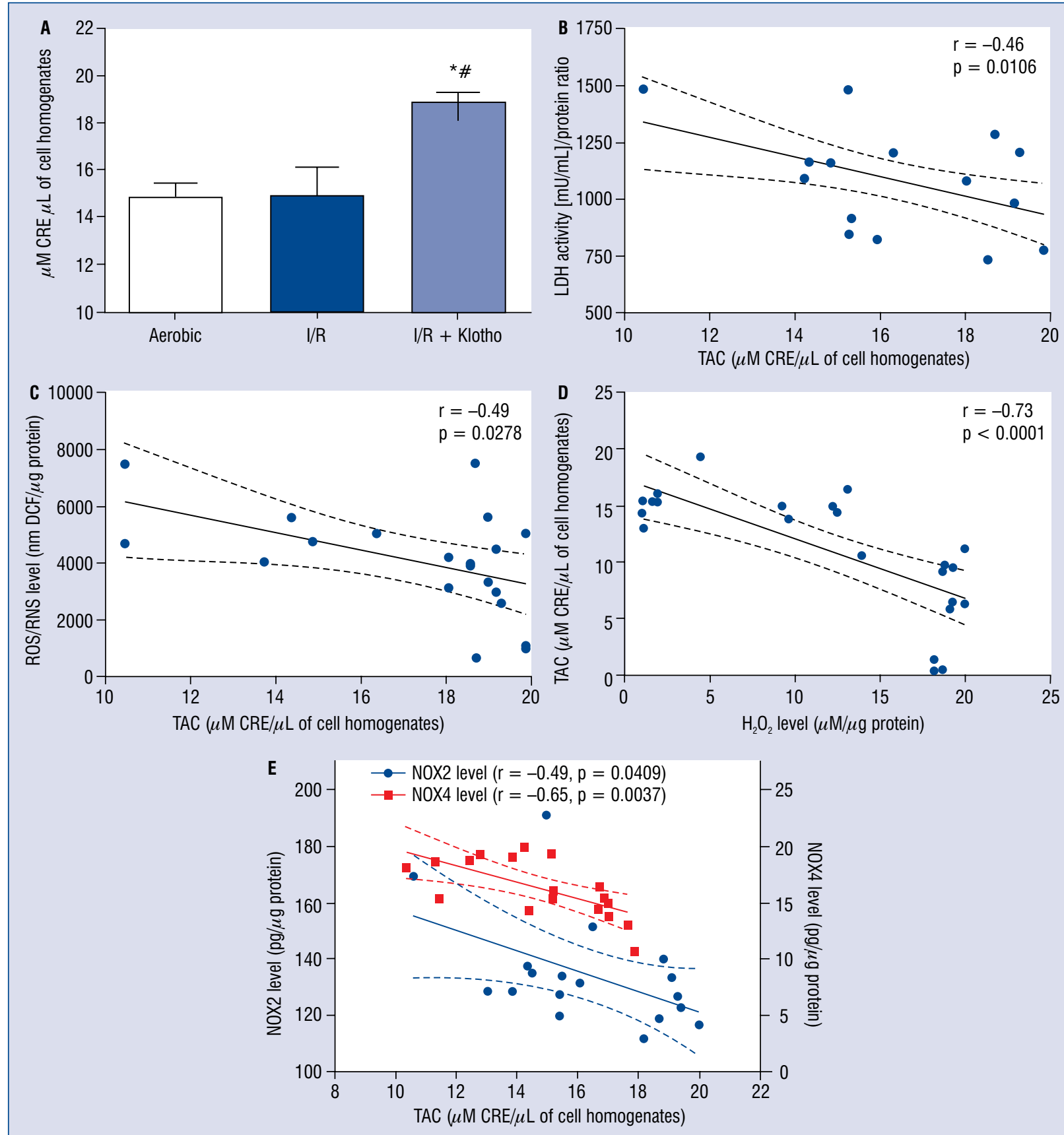

Figure 5. Antioxidant defence in cardiac cells; A. Total antioxidant capacity (TAC) of the cardiomyocytes. TAC was expressed as $\mu \mathrm{M}$ of Copper Reducing Equivalents (CRE) and normalized to $\mu \mathrm{L}$ of cell homogenates; B. Correlation between TAC and lactate dehydrogenase (LDH) activity in the aerobic, ischemia/reperfusion (I/R) and I/R + Klotho groups; C. Correlation between TAC and reactive oxygen species/reactive nitrogen species (ROS/RNS) level in the $\mathrm{I} / \mathrm{R}$ and I/R + Klotho groups; D. Correlation between TAC and hydrogen peroxide $\left(\mathrm{H}_{2} \mathrm{O}_{2}\right)$ level; E. Correlation between TAC, NOX2 and NOX4 levels; DCF - 2', 7'-dichlorodihydrofluorescein; $\mathrm{mU} / \mathrm{mL}$ - milli international enzyme units per milliliter; NADPH - nicotinamide adenine dinucleotide phosphate; NOX2 - NADPH oxidase 2; NOX4 - NADPH oxidase $4 ;{ }^{*} \mathrm{p}<0.05$ vs aerobic control; $\# \mathrm{p}<0.05$ vs. I/R; mean $\pm \mathrm{SEM} ; \mathrm{n}=6$.

$(\mathrm{r}=0.39, \mathrm{p}=0.0318)$ and $\mathrm{ROS} / \mathrm{RNS}$ level $(\mathrm{r}=0.42$, $\mathrm{p}=0.0130$; Fig. 7B), and with NOX2 $(\mathrm{r}=0.47$, $\mathrm{p}=0.0050)$ and NOX $4(\mathrm{r}=0.50, \mathrm{p}=0.0026)$ levels (Fig. 7C). The administration of Klotho protein during $\mathrm{I} / \mathrm{R}$ reduced the production of $\left(\mathrm{NO}_{\mathrm{x}}\right)^{-}$ (Fig. 7A). 


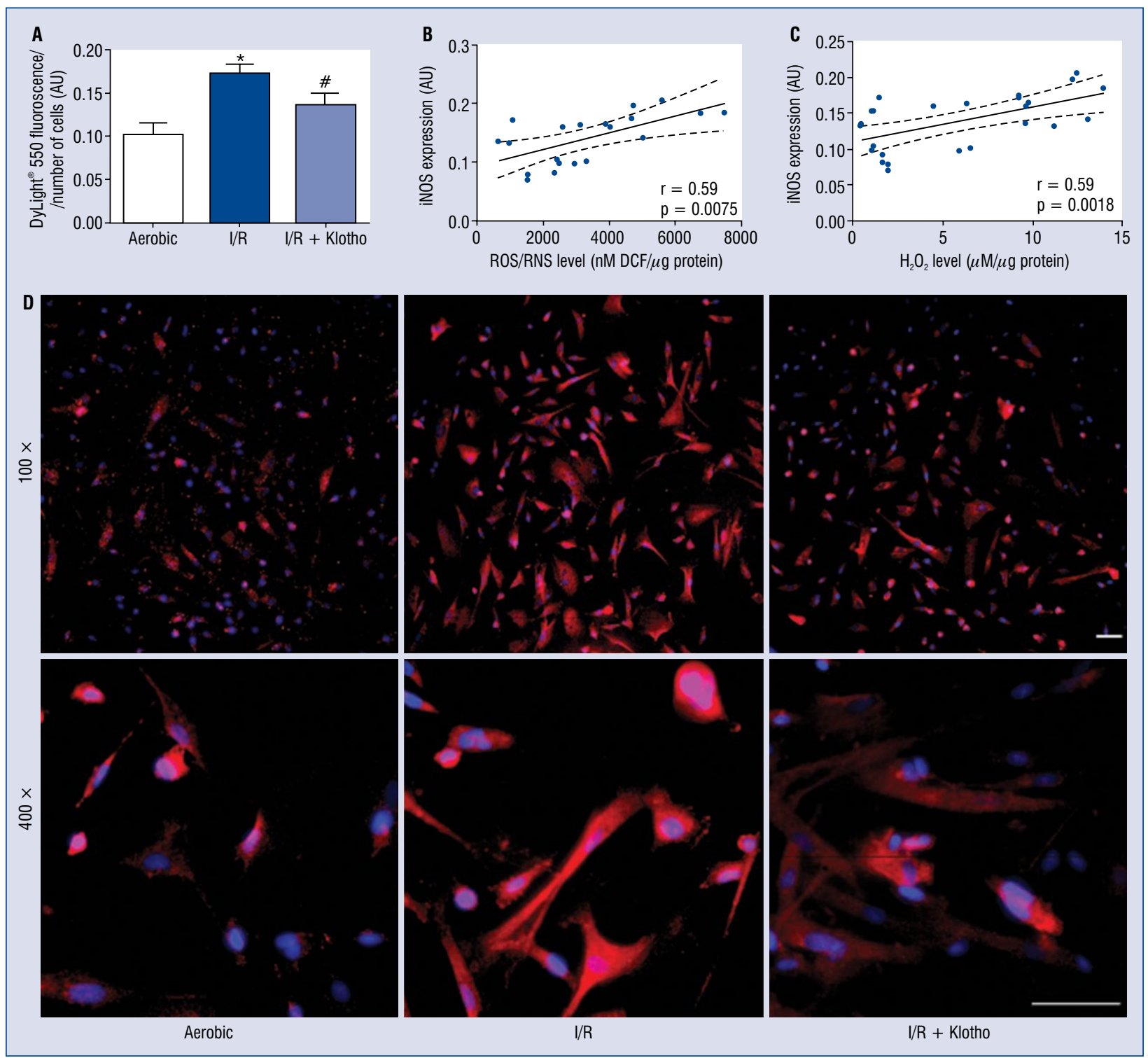

Figure 6. The expression of inducible nitric oxide synthase (iNOS) protein in cardiomyocytes; A. The expression of iNOS protein in the cardiomyocytes; B. Correlation between the iNOS expression and the reactive oxygen species/reactive nitrogen species (ROS/RNS) level; C. Correlation between iNOS expression and hydrogen peroxide $\left(\mathrm{H}_{2} \mathrm{O}_{2}\right)$ level; D. Immunofluorescence staining of cardiomyocytes for iNOS (red fluorescence) and 4',6-diamidino-2-phenylindole (DAPI) for nuclei (blue fluorescence). The expression of iNOS was expressed as arbitrary units (AU) and normalized to total number of cells (blue fluorescence). Graph bars show the average of total cell fluorescence in each experiment; magnification $100 \times$ and $400 \times$; scale bar $100 \mu \mathrm{m}$; DCF -2 ', 7'-dichlorodihydrofluorescein; AU — arbitrary units; ${ }^{*} \mathrm{p}<0.05$ vs. aerobic control; \#p $<0.05$ vs. ischemia/reperfusion (I/R); mean $\pm \mathrm{SEM}$; $n=7-8$.

\section{Metabolic status of cardiomyocytes subjected to I/R injury}

The glucose uptake was reduced in cells from the $\mathrm{I} / \mathrm{R}$ group in comparison to the aerobic control group (Fig. 8A) and negatively correlated with LDH activity ( $\mathrm{p}=0.0002, \mathrm{r}=-0.65)$ (Fig. 8B). The production of lactate was also increased in the cardiomyocytes subjected to I/R compared to the aerobically maintained cells (Fig. 8C). Lactate production positively correlated with $\mathrm{LDH}$ activity $(\mathrm{p}=0.03, \mathrm{r}=0.39)$ and $\mathrm{ROS} / \mathrm{RNS}$ level $(\mathrm{p}=0.0033$, $r=0.64$ ) (Fig. 8D). The administration of Klotho protein normalized glucose uptake (Fig. 8A) and lactate production (Fig. $8 \mathrm{C}$ ) in cells subjected to I/R. 


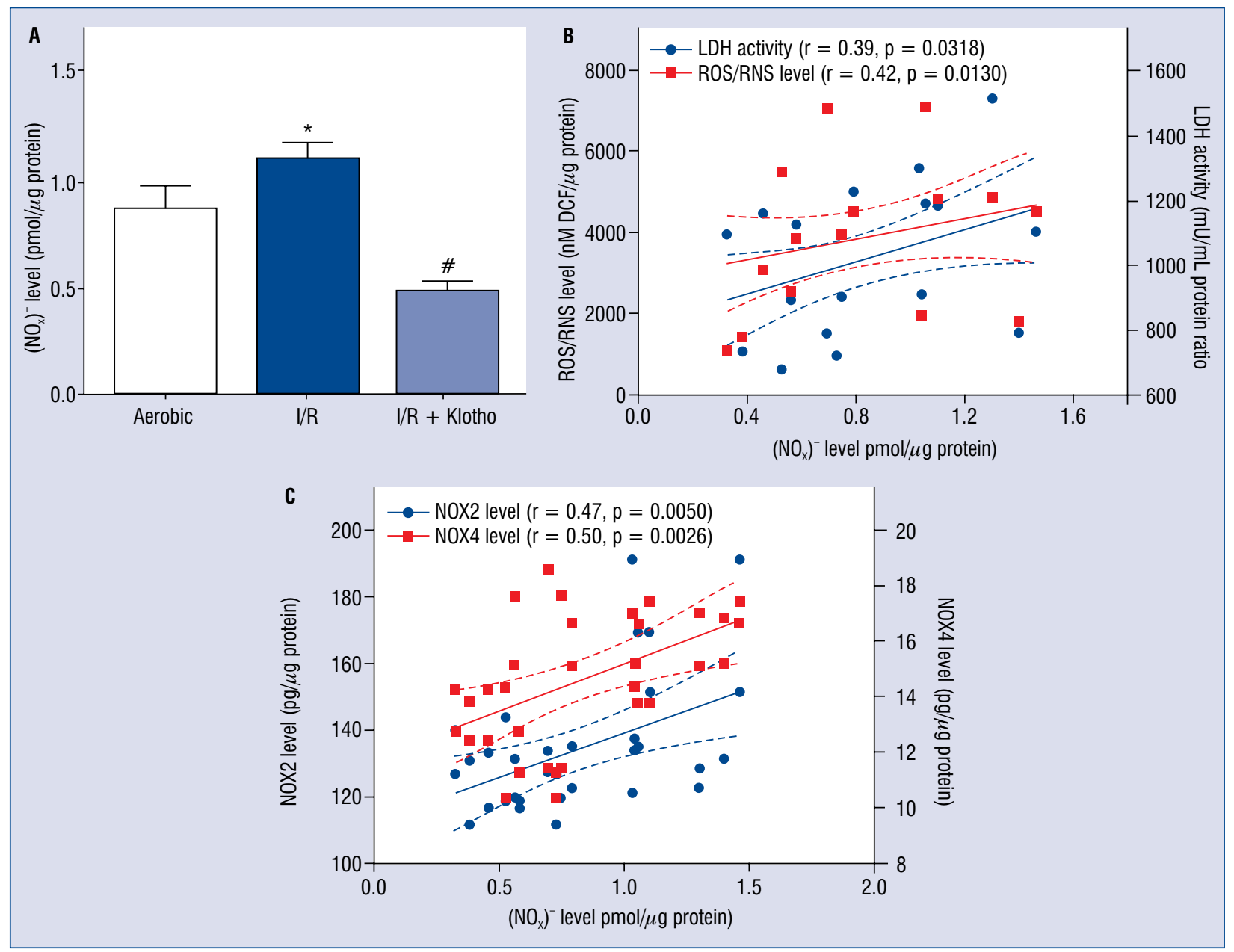

Figure 7. The production of nitric oxide (NO) in cardiomyocytes; $A$. The level of total nitrate/nitrite $\left(\mathrm{NO}_{\mathrm{x}}\right)^{-}$in cardiac cells as an indicator of $\mathrm{NO}$ production. The level of $\left(\mathrm{NO}_{x}\right)^{-}$in cell homogenates was normalized to total protein concentration; B. Correlation between $\left(\mathrm{NO}_{x}\right)^{-}$level, lactate dehydrogenase (LDH) activity and reactive oxygen species/ /reactive nitrogen species (ROS/RNS) level; C. Correlation between $\left(\mathrm{NO}_{x}\right)^{-}$, NOX2 and NOX4 levels; DCF - 2', 7'-dichlorodihydrofluorescein; $\mathrm{mU} / \mathrm{mL}$ - milli international enzyme units per milliliter; NADPH — nicotinamide adenine dinucleotide phosphate; NOX2 - NADPH oxidase 2; NOX4 - NADPH oxidase 4; $\left(\mathrm{NO}_{x}\right)^{-}-$nitrates and nitrites; ${ }^{*} p<0.05$ vs. aerobic control; \#p $<0.05$ vs. ischemia/reperfusion (I/R); mean \pm SEM; $n=10-12$.

\section{Discussion}

Recent studies have shown that Klotho acted in a preventive and therapeutic way in acute renal failure, chronic kidney disease, and ischaemic brain injury [15-20]. For this reason, the present study hypothesised that Klotho protein may contribute to the functioning of a compensatory mechanism that mitigates the initial damage in the heart tissue as well. The current research revealed that Klotho protein participates in the reduction of oxidative/ /nitrosative stress and supports metabolic functions in the cardiomyocytes, showing that Klotho contributes to cardioprotection.
It was proven that higher serum Klotho level correlated with reduced occurrence of cardiovascular events and cardiovascular death in humans [21]. An increased level of the serum Klotho in patients who have had myocardial infarction was observed, and as such, the compensatory production of Klotho to prevent the development of subsequent heart lesions was suggested [22]. Importantly, it was previously shown that a compensative production of the Klotho protein takes place in the cardiomyocytes during I/R to protect cells from further injury [7]. In the current study, increased cell injury in the cardiomyocytes subjected to I/R was shown. The expression of the Klotho gene and protein were 


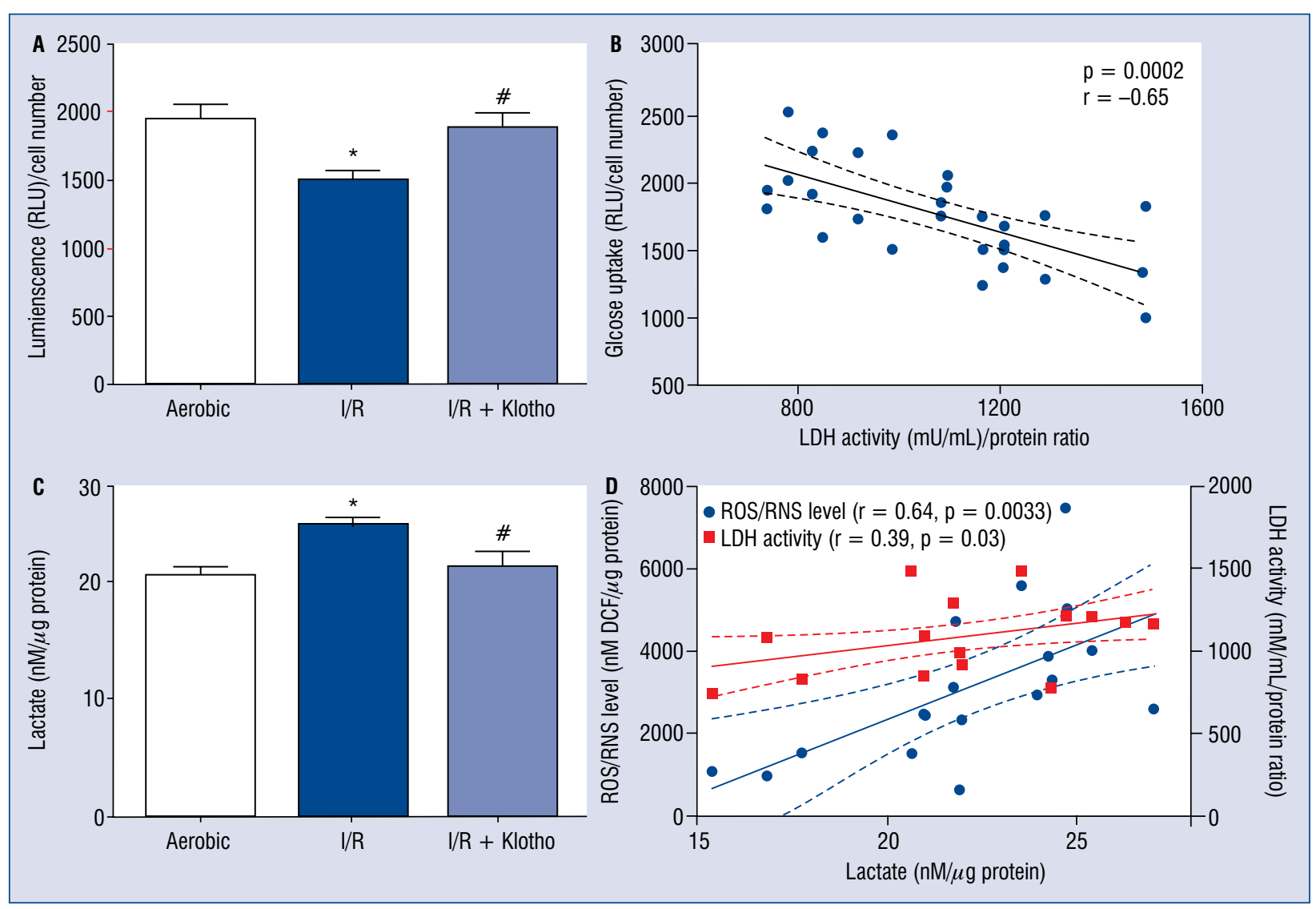

Figure 8. Metabolic status of cardiomyocytes during ischemia/reperfusion (I/R) injury. A. The glucose uptake in the cardiomyocytes subjected to $\mathrm{I} / \mathrm{R}$ with or without Klotho supplementation. The data were expressed in relative lights units (RLU) and normalized to the cell number in each well; B. Correlation between glucose uptake and lactate dehydrogenase (LDH) activity; $\mathbf{C}$. The influence of I/R injury and Klotho protein on the production of lactate in the cardiomyocytes. The lactate concentration was assessed in cell supernatants and normalized to total protein concentration; D. Correlation between lactate level, LDH activity and reactive oxygen species/reactive nitrogen species (ROS/RNS) level; DCF -2 ', 7'-dichlorodihydrofluorescein; $\mathrm{mU} / \mathrm{mL}-$ milli international enzyme units per milliliter; ${ }^{*} \mathrm{p}<0.05 \mathrm{vs}$. aerobic control; $\# p<0.05$ vs. l/R; mean \pm SEM; $n=5-10$.

significantly increased in I/R group and positively correlated with cell damage, suggesting a compensatory expression of Klotho to counteract the injury. Administration of the exogenous recombinant human Klotho protein during I/R regulated the expression of the Klotho gene and production of the Klotho protein in cardiomyocytes to the level observed in aerobic conditions. Herein, it is implied that this change may be due to a negative feedback loop in response to the presence of the exogenous Klotho protein, that requires further investigation. Similarly, Sahu et al. (2018) [23] showed that the expression of the Klotho in the muscles was increased in young mice following an acute cardiotoxin-induced injury. Thus, we suggest that the administration of the Klotho protein may contribute to prevention of damage and reduction of injuries in the cardiomyocytes.
An increasing oxidative stress in the failing heart is mainly caused by inactivation of complex I and the functional uncoupling of the respiratory chain in mitochondria. However, the activity of enzymes like xanthine oxidase, cyclooxygenase, NOS, and NOX is also a source of ROS [24]. NOX is a membrane-bound enzyme complex with activity in the extracellular space. NOX isoforms catalyze production of a superoxide free radical and other ROS, thus representing an important source of ROS [25]. While NOX2 is often referred to as the phagocyte NADPH oxidase, it is also expressed in neurons, cardiomyocytes, skeletal muscle myocytes, hepatocytes, endothelial cells and hematopoietic stem cells, and mainly generate superoxide. NOX4 is highly expressed in the kidney and is responsible for basal $\mathrm{H}_{2} \mathrm{O}_{2}$ production $[25,26]$. It is known that NOX mediates oxidative stress during 
heart, kidney, brain, liver, and lung I/R injury [27]. Moreover, it was reported that NOX2 and NOX4 play an important role in myocardial hypertrophy and/or cardiac remodeling [28]. In the present analysis, the level of NOX2 was significantly higher in I/R cells, while Klotho protein contributed to the reduction of NOX2 and NOX4 expression during I/R. Similarly, an increased NOX2 expression in human cardiomyocytes after acute myocardial infarction was shown [29]. The level of NOX2 and NOX4 was upregulated in a guinea pig model of progressive left ventricular hypertrophy or in the failing heart in mice $[24,30]$. As reported, Klotho decreased NOX2 protein expression in rat aorta smooth muscle cells by influencing the cAMP/ /protein kinase A pathway [31]. A recent study showed that treatment with Klotho suppressed NOX2 and NOX4 expression and inhibited p38 and extracellular signal-regulated protein kinase $1 / 2$ signalling pathways, thus protecting against indoxyl sulphate-inducted myocardial hypertrophy in mice [28]. In the present study, it was observed that Klotho effectively reduced NOX2 and NOX4 expression in I/R injured cardiomyocytes, suggesting cardioprotection. However, it needs to be emphasized that it was preliminary research on Klotho and NOX, thus further analysis to reveal the potential mechanism is needed.

Research over the last few years has revealed that Klotho limited oxidative stress, inflammation and fibrosis in HeLa, as well as in the aortic or renal murine cells [32, 33]. It was shown that Klotho led to the activation of the forkhead box protein $\mathrm{O}$ transcription factors through the inhibition of insulin/insulin growth factor $1 /$ phosphatidylinositol 3-kinase signalling pathway. It resulted in enhanced expression of superoxide neutraliser manganese superoxide dismutase, and consequently, in oxidative stress resistance $[32,33]$. Therefore, it was of interest to investigate whether the administration of a recombinant Klotho protein may limit oxidative stress in cardiac cells as well. An increased production of ROS/RNS and $\mathrm{H}_{2} \mathrm{O}_{2}$ was shown in the cardiomyocytes subjected to I/R. Cardiomyocyte supplementation with exogenous Klotho protein during $\mathrm{I} / \mathrm{R}$ contributed to the reduction of oxidative stress, suggesting the antioxidative potential of Klotho. It was subsequently observed that the TAC of the cardiomyocytes negatively correlated with LDH activity and with ROS/RNS, $\mathrm{H}_{2} \mathrm{O}_{2}$, NOX2, and NOX4 levels, confirming that the intensified damage to heart cells during $\mathrm{I} / \mathrm{R}$ is due to an unbalanced increase in ROS/RNS level, while administration of Klotho significantly enhanced antioxidant activity.
This resulted in the reduction in injury and maintenance of cardiomyocyte function. In addition, studies have shown a decrease in ROS formation, reduced oxidative stress and apoptosis after Klotho protein administration or induction of the Klotho gene expression in the kidneys and brain $[12,16$, 20, 33, 34]. Proposed herein, that Klotho may also support protection of the cardiomyocytes from oxidative stress and damage caused by I/R.

While NO is a relaxing factor in the endothelium and serves as a radical scavenger, in the presence of superoxide during oxidative stress, $\mathrm{NO}$ forms $\mathrm{ONOO}^{-}$which can cause damage in the myocardium $[4,35,36]$. It was previously reported that oxidative stress was a significant source of $\mathrm{NO}$ during $\mathrm{I} / \mathrm{R}$, as well as that NO synthesis in the cardiomyocytes was associated with the induction of high output NOS. The level of $\left(\mathrm{NO}_{\mathrm{x}}\right)^{-}$in cardiac cells was also increased due to I/R [14]. Likewise, in the present study, there was an increased expression of iNOS and intensified production of $\left(\mathrm{NO}_{\mathrm{x}}\right)^{-}$during I/R. The expression of iNOS and $\left(\mathrm{NO}_{\mathrm{x}}\right)^{-}$level positively correlated with the cell injury, NOX2 and NOX4 levels, and with ROS/RNS level, confirming the conception of overproduction of ROS, disrupted NOS expression, and increased production of nitrate/nitrite due to I/R. Recent works on I/R-injured rat hearts proved that the pharmacological regulation of NOS expression and NO bioavailability attenuated cardiac injury and improved the heart's mechanical function [3, 37-39]. In the current investigation, the Klotho protein decreased the expression of iNOS, reduced the production of NO, thus contributing to the protection against nitrosative stress. Interestingly, Klotho deficiency has been linked to the disrupted expression of iNOS in the cardiomyocytes [40]. Regulated NO synthesis in the vascular endothelial cells and improved endothelial function during Klotho overexpression were observed as well [41, 42]. Similarly, Klotho reduced iNOS expression and attenuated NO overproduction in HUVECs or pancreatic beta-cells during stress conditions [43, 44]. The research showed that supplementation of cardiomyocytes with Klotho during I/R, regulated the production of $\left(\mathrm{NO}_{\mathrm{x}}\right)^{-}$to the level observed in the aerobic control group. Thus, Klotho can be recognised as a potential factor that supports the reduction of nitrosative stress in the heart during $\mathrm{I} / \mathrm{R}$.

The studies showed that a switch from lactate uptake to lactate production occurs in the heart during myocardial ischemia [8, 9]. Importantly, an overproduction and accumulation of lactate have been implicated as a factor that causes cellular 
damage during ischemia directly or indirectly [45]. It was previously reported that administration of the Klotho protein supported the viability and recovery of a proper metabolism in I/R-injured cells [7]. In this study, I/R injury led to reduced glucose uptake and increased production of lactate in the cardiomyocytes, confirming unbalanced cellular metabolism. The glucose uptake negatively correlated with the magnitude of injury, indicating disrupted metabolic functions. Importantly, it was reported that an intensified glycolysis is mainly caused by increased net glycogen breakdown rather than high glucose uptake $[8,9]$. The cardiomyocytes under long-time hypoxia showed suppression of cellular glucose metabolism as well [46]. In the current study, the production of lactate positively correlated with cell injury and oxidative/ /nitrosative stress, confirming the mechanism of metabolic disruption during I/R. Administration of the Klotho protein regulated the glucose uptake to the level observed in the aerobic control group and limited subsequent production of lactate in the cardiomyocytes subjected to I/R. Interestingly, increased expression of the GLUT1 glucose transporter, as well as the enhanced glucose uptake and metabolism that followed, prevented apoptosis and the development of heart failure in response to hypoxia or pressure overload in animal models [47-49]. Klotho deficiency led to insulin resistance in the murine skeletal muscle, whereas Klotho overexpression increased glucose-induced insulin secretion in MIN6 beta-cells [50, 51]. It was found that the fibroblast growth factor (FGF) 21 stimulates glucose uptake in adipocytes by the induction of glucose transporters. Since Klotho is a co-receptor for FGF, it could be implicated in the glucose transportation and metabolic homeostasis through $\mathrm{FGF} / \mathrm{FGF}$ receptor/Klotho signalling pathway [52]. Herein, it is reported that the Klotho protein supported glucose uptake and metabolic activity in cardiomyocytes during I/R injury.

\section{Conclusions}

The present research showed that the administration of Klotho during I/R injury contributed to: a) ameliorated cell damage; b) reduced oxidative and nitrosative stress; c) regulated glucose uptake and lactate production in the cardiomyocytes, and therefore, d) Klotho may be considered cardioprotective.

Further research is required to reveal the precise molecular mechanism by which Klotho could be involved in oxidative/nitrosative stress inhibition and glucose uptake recovery in cardiomyocytes during I/R.

\section{Acknowledgments}

This work was prepared under the project financed from the funds granted by the Ministry of Science and Higher Education in the "Regional Initiative of Excellence" program for the years 2019-2022, project number 016/RID/2018/19, the amount of funding 11998121.30 PLN (grant number RID.Z501.19.010).

We kindly thank Cell Service (Poznan, Poland) for its permission to rent the Leica Thunder Imager.

\section{Conflict of interest: None declared}

\section{References}

1. Heusch G, Gersh BJ. The pathophysiology of acute myocardial infarction and strategies of protection beyond reperfusion: a continual challenge. Eur Heart J. 2017; 38(11): 774-784, doi: 10.1093/eurheartj/ehw224, indexed in Pubmed: 27354052.

2. Byrne JA, Grieve DJ, Cave AC, et al. Oxidative stress and heart failure. Arch Mal Coeur Vaiss. 2003; 96(3): 214-221, indexed in Pubmed: 12722552.

3. Krzywonos-Zawadzka A, Franczak A, Olejnik A, et al. Cardioprotective effect of MMP-2-inhibitor-NO-donor hybrid against ischaemia/reperfusion injury. J Cell Mol Med. 2019; 23(4): 2836-2848, doi: 10.1111/jcmm.14191, indexed in Pubmed: 30729745.

4. Tsutsui H, Kinugawa S, Matsushima S. Oxidative stress and heart failure. Am J Physiol Heart Circ Physiol. 2011; 301(6): H2181-H2190, doi: 10.1152/ajpheart.00554.2011.

5. Kuro-o M, Matsumura Y, Aizawa H, et al. Mutation of the mouse klotho gene leads to a syndrome resembling ageing. Nature. 1997; 390(6655): 45-51, doi: 10.1038/36285, indexed in Pubmed: 9363890.

6. Kim JH, Hwang KH, Park KS, et al. Biological role of anti-aging protein Klotho. J Lifestyle Med. 2015; 5(1): 1-6, doi: 10.15280/ jlm.2015.5.1.1, indexed in Pubmed: 26528423.

7. Olejnik A, Krzywonos-Zawadzka A, Banaszkiewicz M, et al. Klotho protein contributes to cardioprotection during ischaemia/ reperfusion injury. J Cell Mol Med. 2020; 24(11): 6448-6458, doi: 10.1111/jcmm.15293, indexed in Pubmed: 32319182.

8. Lopaschuk GD, Stanley WC. Glucose metabolism in the ischemic heart. Circulation. 1997; 95(2): 313-315, doi: 10.1161/01. cir.95.2.313, indexed in Pubmed: 9008441.

9. Stanley WC, Hall JL, Stone CK, et al. Acute myocardial ischemia causes a transmural gradient in glucose extraction but not glucose uptake. Am J Physiol. 1992; 262(1 Pt 2): H91-H96, doi: 10.1152/ajpheart.1992.262.1.H91, indexed in Pubmed: 1733326.

10. Stasiak P, Sznitowska M. Zastosowanie hodowli komórkowych w badaniach biofarmaceutycznych. Farm Pol. 2010; 66(3): 228-234.

11. Lindsey ML, Bolli R, Canty JM, et al. Guidelines for experimental models of myocardial ischemia and infarction. Am J Physiol Heart Circ Physiol. 2018; 314(4): H812-H838, doi: 10.1152/ ajpheart.00335.2017, indexed in Pubmed: 29351451. 
12. Lim SW, Jin L, Luo K, et al. Klotho enhances FoxO3-mediated manganese superoxide dismutase expression by negatively regulating PI3K/AKT pathway during tacrolimus-induced oxidative stress. Cell Death Dis. 2017; 8(8): e2972, doi: 10.1038/ cddis.2017.365, indexed in Pubmed: 28771227.

13. Kalyanaraman B, Darley-Usmar V, Davies KJA, et al. Measuring reactive oxygen and nitrogen species with fluorescent probes: challenges and limitations. Free Radic Biol Med. 2012; 52(1): 1-6, doi: 10.1016/j.freeradbiomed.2011.09.030, indexed in Pubmed: 22027063.

14. Bil-Lula I, Lin HB, Biały D, et al. Subthreshold nitric oxide synthase inhibition improves synergistic effects of subthreshold MMP-2/MLCK-mediated cardiomyocyte protection from hypoxic injury. J Cell Mol Med. 2016; 20(6): 1086-1094, doi: 10.1111/ jcmm.12827, indexed in Pubmed: 26992120.

15. Bradford M. A rapid and sensitive method for the quantitation of microgram quantities of protein utilizing the principle of protein-dye binding. Anal Biochem. 1976; 72(1-2): 248-254, doi: 10.1016/0003-2697(76)90527-3.

16. Sugiura H, Yoshida T, Tsuchiya K, et al. Klotho reduces apoptosis in experimental ischaemic acute renal failure. Nephrol Dial Transplant. 2005; 20(12): 2636-2645, doi: 10.1093/ndt/gfi165, indexed in Pubmed: 16204278.

17. Hu MC, Shi M, Zhang J, et al. Klotho deficiency is an early biomarker of renal ischemia-reperfusion injury and its replacement is protective. Kidney Int. 2010; 78(12): 1240-1251, doi: 10.1038/ ki.2010.328, indexed in Pubmed: 20861825.

18. Hu MC, Shi M, Gillings N, et al. Recombinant alpha-Klotho may be prophylactic and therapeutic for acute to chronic kidney disease progression and uremic cardiomyopathy. Kidney Int. 2017; 91(5): 1104-1114, doi: 10.1016/j.kint.2016.10.034, indexed in Pubmed: 28131398.

19. Qian Y, Guo X, Che L, et al. Klotho Reduces Necroptosis by Targeting Oxidative Stress Involved in Renal Ischemic-Reperfusion Injury. Cell Physiol Biochem. 2018; 45(6): 2268-2282, doi: 10.1159/000488172, indexed in Pubmed: 29550818.

20. Zhou HJ, Li H, Shi MQ, et al. Protective effect of Klotho against ischemic brain injury is associated with inhibition of rig-i/nfkappaB signaling. Front Pharmacol. 2017; 8: 950, doi: 10.3389/ fphar.2017.00950, indexed in Pubmed: 29403373.

21. Marçais C, Maucort-Boulch D, Drai J, et al. Circulating klotho associates with cardiovascular morbidity and mortality during hemodialysis. J Clin Endocrinol Metab. 2017; 102(9): 3154-3161, doi: 10.1210/jc.2017-00104, indexed in Pubmed: 28402487.

22. Paula RS, Souza VC, Machado-Silva W, et al. Serum Klotho (but not haplotypes) associate with the post-myocardial infarction status of older adults. Clinics (Sao Paulo). 2016; 71(12): 725-732, doi: 10.6061/clinics/2016(12)09, indexed in Pubmed: 28076518.

23. Sahu A, Mamiya H, Shinde SN, et al. Age-related declines in $\alpha$-Klotho drive progenitor cell mitochondrial dysfunction and impaired muscle regeneration. Nat Commun. 2018; 9(1): 4859, doi: 10.1038/s41467-018-07253-3, indexed in Pubmed: 30451844.

24. Kuroda J, Ago T, Matsushima S, et al. NADPH oxidase 4 (Nox4) is a major source of oxidative stress in the failing heart. Proc Natl Acad Sci U S A. 2010; 107(35): 15565-15570, doi: 10.1073/ pnas.1002178107, indexed in Pubmed: 20713697.

25. Bedard K, Krause KH. The NOX family of ROS-generating NADPH oxidases: physiology and pathophysiology. Physiol Rev. 2007; 87(1): 245-313, doi: 10.1152/physrev.00044.2005, indexed in Pubmed: 17237347.
26. Dikalov SI, Dikalova AE, Bikineyeva AT, et al. Distinct roles of Nox1 and Nox4 in basal and angiotensin ii-stimulated superoxide and hydrogen peroxide production. Free Radic Biol Med. 2008; 45(9): 1340-1351, doi: 10.1016/j.freeradbiomed.2008.08.013, indexed in Pubmed: 18760347.

27. Simone S, Rascio F, Castellano G, et al. Complement-dependent NADPH oxidase enzyme activation in renal ischemia/reperfusion injury. Free Radic Biol Med. 2014; 74: 263-273, doi: 10.1016/j. freeradbiomed.2014.07.003, indexed in Pubmed: 25017967.

28. Yang Ke, Wang C, Nie L, et al. Klotho protects against indoxyl sulphate-induced myocardial hypertrophy. J Am Soc Nephrol. 2015; 26(10): 2434-2446, doi: 10.1681/ASN.2014060543, indexed in Pubmed: 25804281.

29. Krijnen PAJ, Meischl C, Hack CE, et al. Increased Nox2 expression in human cardiomyocytes after acute myocardial infarction. J Clin Pathol. 2003; 56(3): 194-199, doi: 10.1136/jcp.56.3.194, indexed in Pubmed: 12610097.

30. Li JM, Gall NP, Grieve DJ, et al. Activation of NADPH oxidase during progression of cardiac hypertrophy to failure. Hypertension. 2002; 40(4): 477-484, doi: 10.1161/01.hyp.0000032031.30374.32, indexed in Pubmed: 12364350.

31. Wang Y, Kuro-o M, Sun Z. Klotho gene delivery suppresses Nox2 expression and attenuates oxidative stress in rat aortic smooth muscle cells via the cAMP-PKA pathway. Aging Cell. 2012; 11(3): 410-417, doi: 10.1111/j.1474-9726.2012.00796.x, indexed in Pubmed: 22260450.

32. Takenaka T, Kobori H, Inoue T, et al. [op.4b.02] Klotho supplementation attenuates blood pressure and oxidative stress in diabetes. J Hypertens. 2017; 35(Suppl 2): e38, doi: 10.1097/01. hjh.0000523076.42214.98.

33. Yamamoto M, Clark JD, Pastor JV, et al. Regulation of oxidative stress by the anti-aging hormone klotho. J Biol Chem. 2005; 280(45): 38029-38034, doi: 10.1074/jbc.M509039200, indexed in Pubmed: 16186101.

34. Mitobe M, Yoshida T, Sugiura H, et al. Oxidative stress decreases klotho expression in a mouse kidney cell line. Nephron Exp Nephrol. 2005; 101(2): e67-e74, doi: 10.1159/000086500, indexed in Pubmed: 15976510.

35. Heusch P, Aker S, Boengler K, et al. Increased inducible nitric oxide synthase and arginase II expression in heart failure: no net nitrite/nitrate production and protein S-nitrosylation. Am J Physiol Heart Circ Physiol. 2010; 299(2): H446-H453, doi: 10.1152/ajpheart.01034.2009, indexed in Pubmed: 20511413.

36. Yasmin W, Strynadka KD, Schulz R. Generation of peroxynitrite contributes to ischemia-reperfusion injury in isolated rat hearts. Cardiovasc Res. 1997; 33(2): 422-432, doi: 10.1016/s00086363(96)00254-4, indexed in Pubmed: 9074708.

37. Krzywonos-Zawadzka A, Wozniak M, Sawicki G, et al. A drug cocktail for protecting against ischemia-reperfusion injury. Front Biosci (Landmark Ed). 2020; 25: 722-735, doi: 10.2741/4831, indexed in Pubmed: 31585914.

38. Krzywonos-Zawadzka A, Franczak A, Sawicki G, et al. Mixture of MMP-2, MLC, and NOS Inhibitors Affects NO Metabolism and Protects Heart from Cardiac I/R Injury. Cardiol Res Pract. 2020; 2020: 1561478, doi: 10.1155/2020/1561478, indexed in Pubmed: 32322413.

39. Bil-Lula I, Krzywonos-Zawadzka A, Sawicka J, et al. L-NAME improves doxycycline and ML-7 cardioprotection from oxidative stress. Front Biosci (Landmark Ed). 2018; 23: 298-309, doi: 10.2741/4592, indexed in Pubmed: 28930548. 
40. Corsetti G, Pasini E, Scarabelli TM, et al. Decreased expression of Klotho in cardiac atria biopsy samples from patients at higher risk of atherosclerotic cardiovascular disease. J Geriatr Cardiol. 2016; 13(8): 701-711, doi: 10.11909/j.issn.16715411.2016.08.009, indexed in Pubmed: 27781061.

41. Saito Y, Nakamura T, Ohyama Y, et al. In vivo klotho gene delivery protects against endothelial dysfunction in multiple risk factor syndrome. Biochem Biophys Res Commun. 2000; 276(2): 767-772, doi: 10.1006/bbrc.2000.3470, indexed in Pubmed: 11027545.

42. Saito Y, Yamagishi T, Nakamura T, et al. Klotho protein protects against endothelial dysfunction. Biochem Biophys Res Commun. 1998; 248(2): 324-329, doi: 10.1006/bbrc.1998.8943, indexed in Pubmed: 9675134.

43. Liu Y, Zhang Q. Periodontitis aggravated pancreatic beta-cell dysfunction in diabetic mice through interleukin-12 regulation on Klotho. J Diabetes Investig. 2016; 7(3): 303-311, doi: 10.1111/ jdi.12410, indexed in Pubmed: 27330715.

44. Yang Ke, Nie L, Huang Y, et al. Amelioration of uremic toxin indoxyl sulfate-induced endothelial cell dysfunction by Klotho protein. Toxicol Lett. 2012; 215(2): 77-83, doi: 10.1016/j.toxlet.2012.10.004, indexed in Pubmed: 23085347.

45. Neely JR, Grotyohann LW. Role of glycolytic products in damage to ischemic myocardium. Dissociation of adenosine triphosphate levels and recovery of function of reperfused ischemic hearts. Circ Res. 1984; 55(6): 816-824, doi: 10.1161/01.res.55.6.816, indexed in Pubmed: 6499136.

46. Zhang Y, Liu G, Gao X. Attenuation of protects cardiomyocytes against hypoxic stress through maintenance of glycolysis. Biosci Rep. 2017; 37(6), doi: 10.1042/BSR20170925, indexed in Pubmed: 28894025.
47. Liao R, Jain M, Cui L, et al. Cardiac-specific overexpression of GLUT1 prevents the development of heart failure attributable to pressure overload in mice. Circulation. 2002; 106(16): 2125-2131, doi: 10.1161/01.cir.0000034049.61181.f3, indexed in Pubmed: 12379584.

48. Malhotra R, Tyson DGW, Sone H, et al. Glucose uptake and adenoviral mediated GLUT1 infection decrease hypoxia-induced HIF-1alpha levels in cardiac myocytes. J Mol Cell Cardiol. 2002; 34(8): 1063-1073, doi: 10.1006/jmcc.2002.204ㄱ, indexed in Pubmed: 12234775 .

49. Malhotra R, Brosius FC. Glucose uptake and glycolysis reduce hypoxia-induced apoptosis in cultured neonatal rat cardiac myocytes. J Biol Chem. 1999; 274(18): 12567-12575, doi: 10.1074/ jbc.274.18.12567, indexed in Pubmed: 10212235.

50. Utsugi T, Ohno T, Ohyama Y, et al. Decreased insulin production and increased insulin sensitivity in the klotho mutant mouse, a novel animal model for human aging. Metabolism. 2000; 49(9): 1118-1123, doi: 10.1053/meta.2000.8606, indexed in Pubmed: 11016890.

51. Lin Yi, Sun Z. Antiaging gene Klotho enhances glucose-induced insulin secretion by up-regulating plasma membrane levels of TRPV2 in MIN6 beta-cells. Endocrinology. 2012; 153(7): 3029-3039, doi: 10.1210/en.2012-1091, indexed in Pubmed: 22597535.

52. Donate-Correa J, Martín-Núñez E, Delgado NP, et al. Implications of fibroblast growth factor/Klotho system in glucose metabolism and diabetes. Cytokine Growth Factor Rev. 2016; 28 : 71-77, doi: 10.1016/j.cytogfr.2015.12.003, indexed in Pubmed: 26706229. 